\title{
Relato de caso: Síndrome de Phelan-Mcdermid
}

\section{Case report: Phelan-Mcdermid Syndrome}

\author{
Camila Andrade de Morais Costa ${ }^{1 *}$; Nilo Sebe Tonzar ${ }^{2}$
}

Como citar esse artigo. Costa,

C. A. M; Tonzar,; N. S; Relato de

Caso: Relato de caso: Síndrome

de Phelan-Mcdermid. Revista de

Saúde 2021 Ago/Nov.; 12 (3): 80-83.

\begin{abstract}
Resumo
A Síndrome de Phelan-McDermid ou Deleção do 22q13.3 consiste numa desordem neurológica, gerada por uma mutação genética, que resulta num atraso global de desenvolvimento. O objetivo desse artigo é conscientizar os profissionais de saúde sobre a Síndrome de Phelan-McDermid a partir de um relato de caso, cuja finalidade é de ajudar a reduzir os casos subdiagnosticados, garantindo aos portadores da doença uma melhora na qualidade de vida. O artigo descreve o caso de uma criança, desde o seu nascimento até os 2 anos de idade, a partir do relato dos pais e de análise de relatórios e laudos médicos. Desta forma, consideramos fundamental que os profissionais de saúde conheçam esta síndrome, possibilitando uma maior chance de um diagnóstico correto e, consequentemente um tratamento eficaz, tanto no manuseio do espectro autista, quanto no desenvolvimento neuropsicomotor.
\end{abstract}

Palavras-chave: Síndrome de Phelan-McDermid; Síndrome da Deleção do 22q13.3; Desordens Cromossômicas.

\begin{abstract}
Phelan-McDermid Syndrome or Deletion of 22q13.3 consists of a neurological disorder, generated by a genetic mutation, which results in an overall developmental delay. The objective of this article is to raise health professionals' awareness of Phelan-McDermid Syndrome from a case report, whose purpose is to help reduce underdiagnosed cases, ensuring that the carriers of the disease improve their quality of life. The article describes the case of a child, from birth to 2 years of age, from the parents' report, analysis of reports and medical records. Thus, we consider it essential that health professionals know this syndrome, allowing a greater chance of a correct diagnosis and, consequently, an effective treatment, both in the handling of the autistic spectrum and in the neuropsychomotor development.

Keywords: Phelan-Mcdermid Syndrome; 22q13 Deletion Syndrome; Chromosome Disorders
\end{abstract}

\section{Introdução}

A Síndrome de Phelan-McDermid, é o resultado de uma deleção simples, translocação desequilibrada ou alteração cromossomial estrutural (cromossomos em anel) do braço longo do cromossomo 22, na região 1, banda 3, sub-banda 3. Por esse motivo, também é conhecida como Síndrome da Deleção do 22q13.3. A região do cromossomo que é afetada possui três genes, sendo o mais afetado o SHANK3, que codifica uma proteína de suporte nas densidades pós-sinápticas das sinapses excitatórias, conectando os receptores ligados na membrana aos filamentos de actina no citoesqueleto. Dessa forma, a maioria das desordens neurológicas da síndrome podem ser relacionados a haploinsuficiência de SHANK3.

A apresentação clínica da doença é inespecífica, facilitando seu subdiagnóstico. Dessa forma, é possível explicar o motivo pela qual, mesmo tendo sida descrita a primeira vez em 1985, há somente 1200 casos relatados

${ }^{1}$ Discente do Curso de Medicina, Pró Reitoria de Ciências Médicas, Universidade de Vassouras, Vassouras, Rio de Janeiro, Brasil. ORCID https://orcid.org/0000-0002-4060-7566. 
pelo mundo. ${ }^{2}$

O objetivo desse artigo foi conscientizar os profissionais de saúde sobre a Síndrome de PhelanMcDermid a partir de um relato de caso, cuja finalidade é de ajudar a reduzir o número de subdiagnósticos e garantir aos pacientes portadores da doença uma melhora na qualidade de vida.

\section{Descrição do caso}

MCPP, sexo feminino, branca, nasceu no dia 18/03/2017 na cidade de Vassouras no estado do Rio de Janeiro. Na gestação da paciente, foi relatado que durante a gravidez, a mãe apresentou ITU e leucorreia próxima ao parto, não tratada. O parto foi normal espontâneo com 38 semanas e 6 dias, APGAR 8/8, Ballard de 30 semanas, tempo de bolsa rota de 2 dias, peso de $1800 \mathrm{~g}$, tipagem sanguínea isogrupo com a mãe $(\mathrm{O}+)$ e oligodramnia.

A recém-nascida $(\mathrm{RN})$ teve que ser transferida para UTI devido a quadro de desconforto respiratório grave, necessitando intubação orotraqueal. Na UTI, foi iniciada terapia antibiótica para sepse neonatal precoce suspeita. Além disso, apresentou icterícia nas primeiras 48 horas de vida, sendo tratada com fototerapia por 8 dias. Houve piora do quadro infeccioso da paciente com queda de saturação e bradicardia, até o dia 11/04/2017, sendo iniciado Meropenem 40 mg/Kg/dia e Vancomicina $15 \mathrm{mg} / \mathrm{Kg} /$ dia, que permaneceram por 19 dias. Neste período precisou ser reintubada e colocada em ventilação mecânica. Devido a piora do quadro, foi associado ao esquema de antibiótico, um antifúngico (Anforetericina B -1 mg/Kg/dia), que permaneceu por 14 dias. No dia 14/04/2017, a paciente foi extubada e colocada em ventilação não invasiva (VNI) com pronga nasal. Em 20/04/2017, a RN iniciou um quadro de taquicardia 260 bpm, que não respondeu a manobra vagal com bolsa de gelo, sendo prescrito Amiodarona ( 5 $\mathrm{mg} / \mathrm{Kg} / \mathrm{dia})$. A Amiodarona foi passada para via oral no dia 26/04/2017 e no dia 05/05/2017 teve alta da da UTI. Entretanto, dois dias depois, apresentou novamente arritmia, retornando para Amiodarona venosa, associada a prednisolona devido a risco de pericardite fúngica.

A paciente recebeu alta no dia 11/05/2017, sendo encaminhada para um cardiologista com quadro de taquicardia supraventricular que foi revertida com amiodarona. No dia 19/05/2017 paciente foi novamente avaliada pelo cardiologista que concluiu que tal arritmia tinha evolução benigna, podendo desaparecer após 1 ano de vida, e foi liberada com a prescrição de Amiodarona via oral.

Aos 6 meses de idade, a mãe da paciente percebeu que a lactente não conseguia sustentar a cabeça e procurou uma neuropediatra, sendo solicitado uma Ressonância Magnética (RNM). A médica visualizou alterações no exame e informou aos pais, mas esses não compreenderam, decidindo procurar outro médico para melhor elucidação das alterações.

Aos 9 meses de idade, foi consultada por outra neuropediatra que, após avalição dos exames, constatou uma alteração cerebral, além das repercussões da hipóxia, e aventou a possibilidade de uma doença genética. Diante desta suspeita, encaminhou a paciente para avaliação de especialistas, tais como, avaliação oftalmológica com fundo de olho, avaliação genética, terapeuta ocupacional e fonoaudiologia. Essas avaliações demonstraram haver dismorfias faciais, dimple sacral, sulco interglúteo em $\mathrm{Y}$, macrocrania relativa, atraso global do desenvolvimento, hipotonia e na RNM de crânio demonstrou atrofia parenquimatosa e atraso de mielinização.

Os resultados dos exames oftalmológicos revelaram atraso visual de causa neurológica, sendo indicado uso de óculos para estimulação visual. A mesma iniciou reabilitação com fisioterapia, fonoaudiologia e terapia ocupacional. $\mathrm{Na}$ avaliação genética, o cariótipo da paciente foi normal $(46, \mathrm{XX})$.

Foi encaminhada para um geneticista clínico, que mesmo com o resultado do cariótipo, pediu um exame de Hibridização Genômica por Microarray, que permitiu avaliar mais detalhadamente os cromossomos da paciente. No dia 19/03/2018, foi obtido o resultado de microdeleção do 22q13. Associado a isso, foi confirmado por Amplificação Multiplex de Sondas Dependente de Ligação (MLPA) que tal deleção também incluiu o gene SHANK3. Sendo assim, a paciente foi diagnosticada com Síndrome de Phelan-McDermid.

\section{Discussão}

Importante ressaltar que a primeira suspeita clínica da doença costuma ser a hipotonia neonatal, que pode contribuir para má alimentação, dificuldade de fala, reflexos reduzidos e atrasos motores. Além disso, na fase pré-escolar, a criança tem um vocabulário limitado. Os pacientes com deleção do 22q13.3, podem ter sintomas compatíveis com o autismo, resultado da carência do gene SHANK3. ${ }^{3}$

$\mathrm{Na}$ ectoscopia, a cabeça tende a ser longa ou dolicocéfala, apresenta sobrancelha larga, olhos profundos, pálpebras inchadas, nariz bulboso e cílios longos e grossos. A face intermediária pode ser plana com uma ponte nasal larga e bochechas inchadas, o queixo é frequentemente pontudo e pode se tornar proeminente com a idade, orelhas são tipicamente grandes e podem ser proeminentes ou malformadas. Apresentam mãos carnudas, unhas dos pés displásicas, linfedema e diminuição da percepção da dor. ${ }^{4}$

Pacientes com a Síndrome de Phelan-McDermid podem apresentar transtorno bipolar e perda de 
habilidades. Essa regressão é a mais comum nos indivíduos com mais idade, e costuma ocorrer mais drasticamente após eventos agudos, como choque séptico, estado epiléptico, fase catatônica ou síndrome neuroléptica maligna. ${ }^{5}$

No caso relatado em questão, foi notado pelos pais a hipotonia e atraso motor da paciente aos 6 meses. Com a progressão da idade da mesma foi possível detectar o espectro autista. Além disso, a paciente apresenta dismorfias faciais condizentes com a Síndrome de Phelan-Mcdermid como dolicocefalia, nariz bulboso, ponte nasal larga e queixo pontudo (Figura 1).

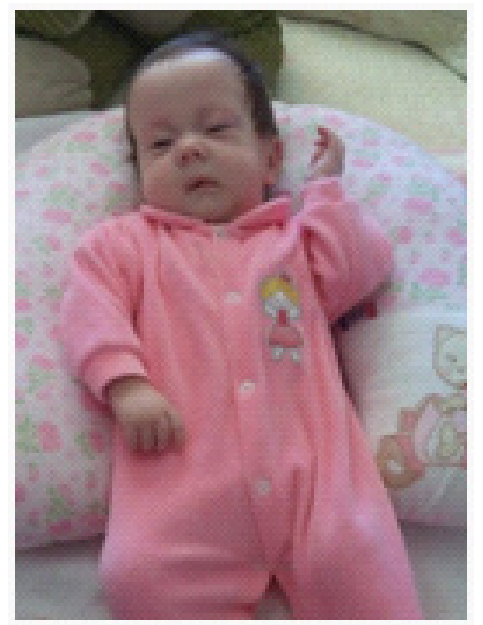

Figura 1. Paciente com características fenotípicas da Síndrome de Phelan.

Fonte: Acervo pessoal do paciente.

As alterações neurológicas são visíveis na Ressonância Magnética de corte sagital, na qual é possível observar alterações hipoplasia do vermis cerebelar, fossa posterior aumentada ou ambos, sem que haja atrofia cerebelar. Dessa forma, relatos prévios de corpo caloso fino e ventriculomegalia são confirmados. 6 $\mathrm{O}$ fraco controle muscular e o comprometimento neurológico podem fazer com que indivíduos com deleção 22q13.3 sejam diagnosticados erroneamente com paralisia cerebral. ${ }^{1}$

O diagnóstico da doença é feito pela Hibridização Genômica por Microarray sendo seguida por rastreio de cariótipo para detecção do cromossomo em anel. Se nenhuma alteração for encontrada, o Teste do Gene Único é realizado primeiro e seguido pela análise de sequência de SHANK3. Além disso, pode ser aplicado o painel multigene que inclua SHANK3 e outros genes de interesse, com a intensão de avaliar os diagnósticos diferenciais 7 como Síndrome de Angelmann, Síndrome de DiGeorge, Síndrome do X Frágil e Síndrome
Kaveggia-Opitz. ${ }^{1}$

Apesar do laudo da RNM da paciente não especificar alterações cerebelares, foi evidenciado alterações parenquimatosas e de mielinização. $\mathrm{Na}$ tentativa de fechar o diagnóstico da paciente relatada, tendo o exame do cariótipo dentro da normalidade, foi solicitado a Hibridização Gênomica por Microrray. Tal exame tem boa especificidade para detecção alterações cromossômicas discretas, como a deleção do 22q13.3. Juntamente a isso, foi confirmado por MLPA a deleção do gene SHANK3, configurando o espectro autista da paciente.

Kolevzon et al. (2014) realizaram um estudo randomizado com 9 crianças com a Deleção do 22q13.3 e do gene SHANK3, no qual foi analisada a ação do IGF-1 nesses pacientes com espectro autista, e constatou uma melhora nas desordens sinápticas dos pacientes com Síndrome de Phelan-McDermid.8 Além desse estudo, há diversos outros que buscam por um tratamento mais adequado para a doença, porém não há um consenso quanto a medicamentos, sendo a terapia não farmacológica a melhor maneira de amenizar as consequências da síndrome.

\section{Considerações finais}

A falta de conhecimento da Síndrome de PhelanMcDermid faz com que muitos médicos a confundam com paralisia cerebral, muitas vezes resultante de encefalopatia hipóxico-isquêmica. No caso relatado, os pais da paciente buscaram conhecimentos a respeito da patologia da sua filha, e ao receberem o diagnóstico da Deleção do 22q13.3, buscaram ajuda multiprofissional para que pudesse melhorar seu neurodesenvolvimento, condição nutricional e consequentemente uma melhor qualidade de vida. Sendo assim, é fundamental o conhecimento dessa patologia pelos profissionais de saúde, incluindo-a nos diagnósticos diferenciais de crianças que apresentem essas características fenotípicas e, consequentemente um tratamento eficaz, tanto para trabalhar o espectro autista, quanto o desenvolvimento neuropsicomotor.

\section{Comitê de Ética}

O relato apresentado foi aprovado pelo Comitê de Ética e Pesquisa da Universidade de Vassouras, parecer $\mathrm{n}^{\circ}$ 4.339.960, CAAE 38114620.1.0000.5290, de 15 de outubro de 2020.

\section{Referências}

1 - Phelan K, McDermid HE. The 22q13.3 Deletion Syndrome (PhelanMcDermid Syndrome). Mol Syndromol. 2011;2:186-201. 
2 - Hernández-Gómez M, Meléndez-Hernández R, Ramírez-Arroyo E, Mayén-Molina DG. Síndrome de Phelan-McDermid: reporte de un caso y revisión de la literatura. Acta Pediatr Mex. 2018;39(1):42-51.

3 - Oberman LM, Boccuto L, Cascio L, Sarasua S, Kaufmann WE. Autism spectrum disorder in Phelan-McDermid syndrome: initial characterization and genotype-phenotype correlations. Orphanet Journal of Rare Diseases. $2015 ; 10: 105$

4 - Kolevzon A, Angarita B, Bush L, Wang AT, Frank Y et al. PhelanMcDermid syndrome: a review of the literature and practice parameters for medical assessment and monitoring. J Neurodev Disord. 2014;6(1):39.

5 - Denayer A, Van Esch H, de Ravel T et al. Neuropsychopathology in 7 Patients with the 22q13 Deletion Syndrome: Presence of Bipolar Disorder and Progressive Loss of Skills. Mol Syndromol. 2012;3(1):14-20.

6 - Aldinger KA, Kogan J, Kimonis V, et al. Cerebellar and posterior fossa malformations in patients with autism-associated chromosome 22q13 terminal deletion. Am J Med Genet A. 2012;161A(1):131-6.

7 - Phelan K, Rogers RC, Boccuto L. Phelan-McDermid Syndrome. 2005. In: Adam MP, Ardinger HH, Pagon RA, et al., ed GeneReviews ${ }^{\circledR}$ [Internet]. Seattle (WA): University of Washington, Seattle; 1993-2019. Disponível em: https://www.ncbi.nlm.nih.gov/books/NBK1198.

8 - Kolevzon A, Bush L, Wang AT, et al. A pilot controlled trial of insulin-like growth factor-1 in children with Phelan-McDermid syndrome. Molecular Autism 2014, 5:54. 